\title{
Prevalence of narcolepsy in patients with H63D syndrome
}

Dr. Carolina Diamandis ${ }^{1}$, Anastasios Papadopoulos ${ }^{2}, \mathrm{Riku}_{\mathrm{H}} \mathrm{Honda}^{2}$, Alexandros Balaskas ${ }^{3}$, and Seideman David ${ }^{3}$

${ }^{1}$ Affiliation not available

${ }^{2}$ International H63D Consortium

${ }^{3}$ Lazar Clinic Group (LCG) Rare Diseases Research Consortium, Rare Diseases Research Consortium Kifissias 16

May 10, 2021

\section{Hosted file}

Prevalence of narcolepsy in patients with H63D Syndrome.pdf available at https://authorea. com/users/410930/articles/521271-prevalence-of-narcolepsy-in-patients-with-h63d-syndrome 